International Journal of Instruction e-ISSN: 1308-1470 • www.e-iji.net

Article submission code: 20210219183013

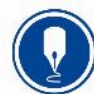

January $2022 \bullet$ Vol.15, No.1

p-ISSN: 1694-609X

pp. 945-964

Received: 19/02/2021

Revision: 22/08/2021
Accepted: 18/09/2021

OnlineFirst: 10/12/2021

\title{
Extending the Theory of Planned Behavior: A Case of Learning Chinese as a Third Language
}

\section{Fouzia Rahman}

School of International Studies, Communication University of China, China, fouziarahman90@gmail.com

\section{Imran Mahmud}

Daffodil International University, Bangladesh \& Graduate School of Business, Universiti Sains Malaysia, Malaysia, imranmahmud@daffodilvarsity.edu.bd

\section{Bingqing Jiang}

Hunan University of Humanities, Science and Technology, China, jbq69@ 126.com

\section{Kaushik Sarker}

Department of Software Engineering, Daffodil International University, Bangladesh, kaushik.swe@daffodilvarsity.edu.bd

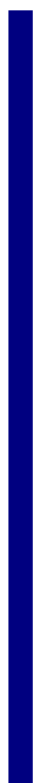

Language has always been considered the most effective medium of communication among humans to express their thoughts, opinions, and emotions. As a consequence of globalization, a lot of people end up living, studying, working, and travelling in countries where both their first and the second languages may not be used. This situation creates a need for learning a third language (L3) considering proficiency in first (native) and second (presumably English) languages. Numerous studies have been conducted on L2 and a lot in the field of L3. However, this study found a scope to research specifically on the language (L3) learning intention in terms of its usefulness for international students who are in a country where their native language and the L2 are not in use. More than 161 international students studying under the Chinese Language Learning program as well as students studying in graduate and undergraduate levels at public universities in Yunnan, Beijing, Jiangsu, and Hunan in China participated in this study. By extending the theory of planned behavior with the Self Determination Theory (SDT), along with the influence of the L2, a survey questionnaire was prepared and data was collected from these participants. Later, the data was analyzed by common method variance and path model estimation of Partial Least Square (PLS) algorithm to generate and evaluate predictions for intentions of learning Chinese as the L3 considering the perceived usefulness of the language which eventually validates the mentioned theories.

Keywords: learning Chinese as 13 , third language acquisition, language learning intention, pls, perceived usefulness, Chinese

Citation: Rahman, F., Mahmud, I., Jiang, B., \& Sarker, K. (2022). Extending the theory of planned behavior: a case of learning Chinese as a third language. International Journal of Instruction, 15(1), 945-964. https://doi.org/10.29333/iji.2022.15154a 


\section{INTRODUCTION}

Language is a conventional written or spoken medium of expression among humans all over the world. The basic functions of language include communication, the expression of identity, play, imaginative expression, and even emotional release among human beings. Individual language learning strategies of learners have become an area of major concentration for the researchers in the field of linguistics (Rahman, 2016). Several studies have been found regarding the L3 or multi language, however a very few concerned the intention of the learners, in certain circumstances, for learning a third language. A number of investigations into individual differences for learning a third language have occurred due to some variables including cognitive, affective and social factors (Jessner, 2006). The diversity of student types, learning goals, self regulated learning strategies (Tran et al., 2021) some psychological factors, or even motivational factors have been employed in many studies claiming learning strategies are the steps taken by the learners to enhance their own learning (Oxford et al., 1989). There may also be a relation between learning any foreign language and the sociocultural identity of the learners as shown by Habib (Habib \& Siros, 2019). While coming to China, most of the non-Chinese students learn Chinese as a third or later language and they use a nonChinese language as lingua franca (Wang, 2013). In most cases that lingua franca is English. Here English is used as a bridge to understand the conversation, especially the conversation with the language instructor (House, 2002). For the majority of the international students there, the common lingau franca to learn Chinese could be English and therefore the fluency in this language may become influential in learning the third language (Jessner, 2006).

The theory of planned behavior and extended theory of planned behavior (Aizen, 1990, 2005) (Teo, 2016) indicates that behavioral intentions have an influence on learning for human beings. It has been established that attitude, subjective norm, perceived behavioral control, and perceived usefulness may have an impact on learning. Therefore, these measuring criteria can be useful in determining the intention of learning a third language. On the other hand, self-determination theory explains that internal and external motivation as well as negative motivation may also have positive and negative influences on learning a new language, especially learning a second or later language (Noels et al., 2000). A group of authors (Parvin et al., 2019) recently have found in their study that attitude and motivation play a key role for the intention of learning English for specific purposes such as aviation communication.

For this research, respondents with different demographic properties participated in a structured-based questionnaire survey. Data collected from the survey was then analyzed through IBM SPSS and predicting algorithms in smartPLS (Shmueli et al., 2016, Ringle et al., 2015) to find out and analyze the relations between factors and then be finally compared to the hypotheses that were made earlier during the planning and model development stage of this research. Before discussing the hypotheses and constructs, two research questions were proposed.

"To what extent, the extended TPB and SDT explain the learning intentions of Chinese as a third language?" and "Which factors are significant, and which are influential for 
determining the intentions of learning the L3 as far as usability of the language is concerned?" Based on these two questions, hypotheses and constructs are developed from the review literature in the next section.

\section{Literature Review}

The Theory of Planned Behavior, widely known as TPB, was first proposed and published by Ajzen (Ajzen, 1985). According to the theory, human behavior can be explained by three factors - behavioral beliefs, normative beliefs, and control beliefs. Later Ajzen (Ajzen, 1991, 2002) proposed further explanation to this behavioral theory and aggregated that behavioral beliefs can lead to favorable or unfavorable attitudes and normative beliefs, which may result in subjective norm and control belief may turn into perceived behavioral control. Thus, these three factors are influential in identifying a person's intention to display a particular behavior and how hard a person may attempt to embrace a particular behavior. Therefore, it can be concluded from Ajzen's (Ajzen, 2002) research that the Perceived Behavioral Control (PBC), Attitude Towards Behavior (ATB), and Subjective Norms (SN) can lead to the formation of behavioral intention. Later, TPB was widely applied and used in numerous researches. In most of the research, the focus was on understanding the role of intention. In addition to these studies, in later times, other relevant models were proposed by several authors. One of the models is Technology Acceptance Model, widely known as TAM, proposed by Davis (Davis et al. ,1989). Instead of subjective norms from TPB it used perceived usefulness, which further suggested that perceived usefulness can be used to understand the determinants of the user's intention to adopt or learn. Another author (Venkatesh et al., 2003) proposed Unified Theory of Acceptance and Use of Technology (UTAUT). This theory has been synthesized from various distinct theoretical models that explain human behavior. Therefore, at times, these theories are required to be extended to fit into a scenario. Thus, extended theories emerged, which are frequently used in many models.

To predict university students' intention to use information systems, Mathieson (Mathieson, 1991) used both TAM and TPB and compared the results. Thus, it can also be decided that comparison between different models is well-accepted for any study as far as these theoretical models and postulates are concerned. In their article Fiahbein and Ajzen (Fishbein \& Ajzen, 1975) first introduced that belief, attitude, and intention were linked to demonstrate a behavior, and later provided theories for behavioral interventions. Ajzen (Ajzen, 2005) explained that changes in these factors may have changes in behavioral intentions. Thus, several extensions of this theory emerged earlier and several new factors were proposed, which were later known as extended theories of planned behavior. A few of such factors can be perceived case of use and perceived usefulness. When use of something requires adoption of a new thing or new technology, and when it is further perceived as easy to use, then a positive attitude is likely to develop for that use (Venkatesh et al., 2000, 2003). Davis (Davis et al., 1989) in his research previously proposed that while learning or adopting something new, if the user or learner perceives the new thing to be useful, then a positive attitude is developed and the attitude may become influential to learn or adopt that new thing. 
Based on past literature and recent published works, it is found that perceived usefulness, along with factors from TPB can be useful in determining the intention of a learner adopting or learning anything. TPB along with its extension have been in use in many researches. It has been supported in determining the intention of using technology where perceived usefulness influenced using attitude (Teo, 2011; Wong et al., 2013). To explain the intention of using or adopting technology among university students, perceived usefulness can be an influential factor and this was proved in the research by Teo and Zhou (Teo \& Zhou, 2014). Using the same approaches to determine the intention to use technology, Teo (Teo et al., 2016) utilized the extended theory of planned behavior and explored the perceived usefulness alongside the factors of TPB. Zoliat (Zoliat, 2014) explored and proposed the extension of perceived behavioral control and identified components of it, which proves the acceptance of such extended theories. Subjective norm was tested to determine the intention to adopt new media production technology (Hopp, 2013). The effect of attitude towards behavior and subjective norm were tested against the usage of mobile phones by Azam (Azam et al., 2013). To explain the attitude and intention to play online games, Alzahrani (Alzahrani et al., 2016) extended the theory of planned behavior (TPB) and successfully conducted their research.

On the other hand, Self Determination Theory (SDT) may be used to explain the learning intention and motivation to learn, and adopt a new language (Noels et al., 2000; Deci \& Ryan, 1985). Researchers of social psychology and education from the past have always recognized the importance of motivation in learning a new language such as L2 (Gardner, 1985). Later, many researchers said that researchers for L2 learning may need to explore factors which might not only be directly related to the L2 motivation (Crooks \& Schmidt, 1991; Schmidt et al., 1996), which further suggested that there might be indirect factors. Learning of language is sustained by attitude and orientations. This was the basic language learning motivation suggested by Gardber (Gardner, 1985). Later, the discussions shifted from attitude and orientations to the nature of language learning motivation (Tremblay \& Gardner, 1995), and to explore and consider alternative motivational models (Dornyei, 1990, 1994; Wen, 1997; Brown, 1990; Clement et al., 1994) however, by not replacing the existing models but complementing them. In such alternative motivational models, proposed by several researchers in the past, the distinction between the intrinsic and extrinsic motivation has caught the eyes of several researchers (Brown, 1994; Deci \& Ryan, 1985; Vallerand, 1997). Intrinsic motivation is the motivation to engage in any activity, which will seem enjoyable and satisfying (Deci \& Ryan, 1985). Later, as complement to this model, Vallerand (Vallerand et al., 1989, 1992, 1993) proposed knowledge accomplishment and stimulation as further extensions to intrinsic motivation.

Extrinsic motivation on the other hand refers to achieving an end result like reward or loss. These motivations come from external sources to a person as countable benefits or loss, which in the case of language learning seems, not to find motivation for engaging in learning if the reason is taken away (Gardner \& MacIntyre, 1991). Finally, the amotivation proposed by Deci and Ryan (Deci \& Ryan, 198), refers to the situation when no relation is found between the action and consequence and thus the learner may 
lose the motivation to learn a new language. Thus, to understand the L2 motivation for learning intention, intrinsic motivation, extrinsic motivation, and amotivation can used as constructs and is used in many significant research done by Dickinson, (Dickinson, 1995), Kamada, (Kamada, 1986), Skehan, (Skehan, 1989), Ushioda (Ushioda, 1996). Therefore, it can also be assumed to be useful in L3 learning motivation as well.

With rapid growth of China's trade and business, economy, and education, learning Mandarin Chinese (which is known as "Putonghua" in the People's Republic of China) was a must for foreigners in the past few decades (Dangpin, 2010). A large number of international students visit China every semester to pursue educational courses. While staying in China most of them learn Chinese as their third (even fourth or fifth) language using English (in most cases second language) as lingua franca (Fang, 2017). Though the origin of lingua franca is little known, it has a wide range of meaning and a variety of uses. Majorly, it means the bridge or vehicle language between speakers of different native languages while having intentions to understand others in any conversation (House, 2002). While learning a new language, it might become necessary to understand what the language instructor is trying to express, therefore, lingua franca could prove to be useful in such situations where the native language of the learners is not used. Several factors have been identified (Wang, 2013) while having an interlanguage transfer under the Cross Linguistic Influence (CLI) during learning a third language. Jessner (Jessner, 2006) in her book "Linguistic Awareness in Multilinguals" referred to the learning and acquisition of a third language and has for a long time been subsumed under research on second language learning and acquisition. However, some groups of scholars are convinced that learning a second language differs in many respects from learning a third language. According to them, Third Language Acquisition (TLA) and trilingualism, is the learning process and its products are not only more complex but also require different skills of the learner. That is, apart from all the individual differences and social factors that affect SLA, the process of learning and the product of learning a second language can potentially exert influence on the acquisition of a third language (Cenoz et al., 2001). Such research study may utilize the survey through questionnaires. To determine the experience and expertise on a particular language, Language Experience and Proficiency Questionnaire (LEAP-Q) (Viorica et al., 2007) can be utilized to assess the language profile in multilingual environment and thus the questionnaire can be used as an inspiration to L3 learning intention research to some extent. Survey questions can be prepared by previous works where self-determination theory was in use (Noels et al., 2000) and inspired by questionnaires prepared by researchers, who extended the theory of planned behavior (Teo et al., 2016).

\section{Constructs Identification and Model Development}

From the reviewed literature it is quite clear that learning L3 is quite possible for persons who intend to learn a language for a specific purpose. The purpose could be related to higher standard of living, migration to abroad, study, and research. The usefulness of learning a third language may not seem obvious, rather it may be perceived. As far as extended theory of planned behavior is concerned, perceived usefulness of learning something falls under behavioral intention and since this research 
relates to analysis of the learning intention keeping this perceived usefulness of the intended language in mind, the following construct can be written:

\section{L3 Learning Intention Based on Perceived Usefulness (L3LIPU)}

The above construct will be tested through presumed relations with other constructs which will be written as hypotheses. Following are three constructs, written keeping the self-determination theory in mind, assuming that intrinsic motivation, extrinsic motivation and negative motivation, which in this case will be referred as amotivation, will play significant roles determining the learning intention:

\section{Relationship between SDT and Learning Intention}

Intrinsic Motivation (IM): Motivation that comes from within oneself, and in this case, the motivation that thrives to learn L3 keeping the perceived usefulness in mind. Therefore, the following hypothesis H1, can be drawn as follows.

H1. Intrinsic motivation has a significant and positive influence towards L3LIPU.

Extrinsic Motivation (EM): Motivation that comes from outside, through other means, which also pushes someone to learn L3, by aiming for the usefulness after completion of the learning. Thus the following hypothesis can be concluded as follows.

H2. Extrinsic motivation has a significant and positive influence towards L3LIPU. Amotivation (AM): Counter motivation that demotivates oneself from learning. Therefore, the following hypothesis from this construct can be written as follows.

H3. Amotivation has a significant and negative influence towards L3LIPU.

\section{Relationship between L2 Fluency and Learning}

Fluency and expertise in a second language can be a significant factor for learning a L3 since L3 can be a completely new language, which may not have any relation to L1 or L2. In this case, Chinese as L3, international students from countries, where their native language is different and learned a worldwide common language. If the instructor uses that common language (lingua franca) in the learning process and activities of L3, then does it helps positively with the learning intention, is under this construct and thus the following hypothesis can be written:

L2 Fluency (L2F): Fluency in L2 that might impact on the intention of learning the L3.

H4. Fluency in L2 (English) has a significant and positive influence towards L3LIPU.

Extended theory of planned behavior focuses on behavioral intention and on the idea that to learn anything significant, the intention matters. This research focuses on the intention of learning an L3, rather than actual learning of the language. Thus the primary construct with which all other constructs and hypotheses are related, also drawn from this extended theory of planned behavior. Being inspired by Teo (Teo et al., 2016) and Ajzen (Ajzen, 2005), the following constructs may be written to determine the learning intention keeping the perceived usefulness of learning L3 in mind. 


\section{Relationship between TPB and Learning intention}

Perceived Behavioral Control (PBC): Behavioral control which is influenced by other factors may pose a great connection to learning intention. Therefore, the following hypothesis can be assumed.

H5. Perceived behavioral control has a significant and positive influence towards L3LIPU.

Attitude Towards Learning (ATL): Learning attitude that may strongly relate with learning intention. The following hypothesis thus be:

H6. Attitude towards learning has a significant and positive influence towards L3LIPU.

Subjective Norm (SN): The last construct in this research which may have a significant relation to the learning intention of the specified L3.

H7. Subjective norm has a significant and positive influence towards L3LIPU.

\section{METHOD}

As per the above proposed model, a structured questionnaire was designed to seek feedback from the participants who are actually learning Chinese as L3 or later. As far as such research is concerned, preparing a questionnaire is a daunting task as questions should be valid for receiving feedback and, at the same time, reliable and quantifiable. The survey questionnaire prepared by the authors, was inspired from previous published works and its questionnaire, which have been proved valid and quantifiable.

Questionnaire was prepared being inspired by recent questionnaires on Theory of Planned Behavior and Self Determination Theory and then improvised for L3 learning intention. The authors modified and used structured questionnaire of previous referred and published researches in the similar area where relevant questions are taken from well accepted specific questionnaire to make the result of this study well accepted to the research community (Ajzen, 1991; Alzahrani et al., 2021; Burnkrant \& Page, 1988; Compeau \& Higgins, 1995; Davis et al., 1989; Harter, 1982; Kruidenier \& Clemen, 1986; Mahmud et al., 2020; Noels et al., 2000; Ryan \& Connell, 1989; Satter et al., 2021; Taylor \& Todd, 1995; Teo et al., 2016; Thompson et al., 1991; Vallerand et al., 1992, 1993).

While developing the questionnaire, a mapping to the constructs with reference was also developed to throw light on the sources that were used to come up with these questions.

\section{Proposed Model}

A hypothesis model is now required to be drawn, as based on this model the surveyed data is fed to specific software to perform common method validity, composite reliability, discriminant validity and factor analysis. Later the model to be examined for full co-linearity test for the path coefficient and P-value. Then finally tests the hypotheses which were prepared to find out the learning intention to learn Chinese as L3. 
At the end this model is drawn again with the results from the analysis to justify the model and to come to a conclusion regarding the study of this research. Further explanation is provided later in the data analysis section and in the result discussion section.

The proposed research model based on the seven hypotheses should satisfactorily answer the research questions presented earlier in the introduction section. The model is shown in the following figure with all hypotheses and constructs. The figure presents the constructs with their hypothesized relationship to the primary construct. From now on, the constructs and hypotheses will be referred to in their concatenated forms.

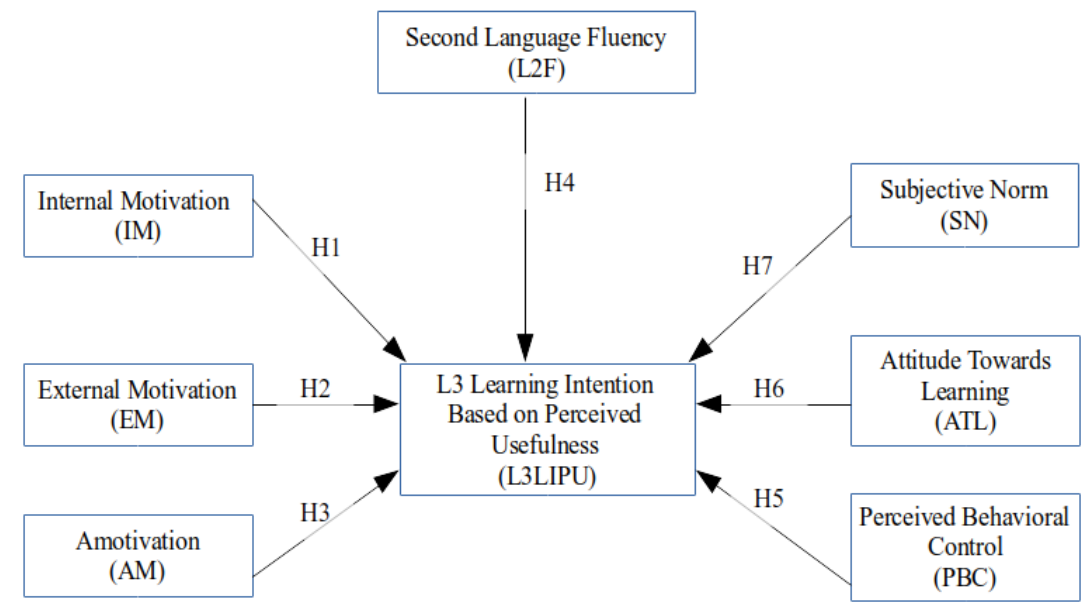

Figure 1

Proposed hypothesis model

\section{Demographic Data of Respondents}

Respondents are the international students from four public universities from four provinces in China, Yunnan Technology and Business University in Kunming, Yunnan, Communication University of China in Beijing, Yangzhou University in Jiangsu and Hunan University of Humanities Science and Technology in Hunan. These students either have learnt or they are learning Chinese as a third or later language.

The first part of the questionnaire that was provided to the students consisted of (6 variables) questions to know about their profiles. To get a good and effective response from the respondents, the questionnaire was provided in English and was further explained either in their native or in their second language with the help of a volunteer interpreter. Based on the responses from the survey, the following table was prepared with the help of SPSS software.

Table 1 shows the demographic data of the respondents where it is seen that $64 \%$ of the respondents are males and the rest are females. More than half (55\%) of the respondents' age are between 21 to 25 years. It has been found that almost $40 \%$ students have passed college education and are now undergraduate students, $15 \%$ have passed honors and are 
at present pursuing master's degree courses, and 7\% of the respondents were found to be enrolled in $\mathrm{PhD}$ courses. Sixty seven percent of the respondents were proficient in two languages and $25 \%$ of them were proficient in three languages.

Table 1

Demographic data of participants

\begin{tabular}{|c|c|c|c|c|c|c|c|}
\hline Variable & Category & Freq. & $\%$ & Variable & Category & Freq. & $\%$ \\
\hline \multirow[t]{2}{*}{ Gender } & Male & 103 & 64 & \multirow[t]{29}{*}{ Country } & Ethiopia & 3 & 1.9 \\
\hline & Female & 58 & 36 & & Germany & 1 & .6 \\
\hline \multirow[t]{4}{*}{ Age } & $<20$ & 53 & 33 & & India & 1 & .6 \\
\hline & $21-25$ & 89 & 55 & & Indonesia & 9 & 5.6 \\
\hline & $26-30$ & 17 & 10.5 & & Kazakhstan & 1 & .6 \\
\hline & $>30$ & 2 & 1.5 & & Laos & 4 & 2.5 \\
\hline \multirow[t]{8}{*}{ Education } & School & 2 & 1.2 & & Malaysia & 1 & .6 \\
\hline & H. School & 28 & 17.4 & & Mongolia & 9 & 5.6 \\
\hline & College & 61 & 37.9 & & Nepal & 3 & 1.9 \\
\hline & P. Training & 7 & 4.3 & & Netherlands & 1 & .6 \\
\hline & Diploma & 16 & 9.9 & & Nigeria & 1 & .6 \\
\hline & Hons & 25 & 15.5 & & Pakistan & 22 & 13.7 \\
\hline & Masters & 11 & 6.8 & & Russia & 3 & 1.9 \\
\hline & Others & 11 & 6.8 & & Rwanda & 2 & 1.2 \\
\hline \multirow{6}{*}{$\begin{array}{l}\text { Language } \\
\text { Known }\end{array}$} & 1.00 & 4 & 2.5 & & Serbia & 2 & 1.2 \\
\hline & 2.00 & 107 & 66.5 & & Somalia & 1 & .6 \\
\hline & 3.00 & 40 & 24.8 & & South Korea & 1 & .6 \\
\hline & 4.00 & 4 & 2.5 & & Sri Lanka & 3 & 1.9 \\
\hline & 5.00 & 3 & 1.9 & & Tajikistan & 8 & 5.0 \\
\hline & 6.00 & 3 & 1.9 & & Tanzania & 5 & 3.1 \\
\hline \multirow{6}{*}{$\begin{array}{l}\text { Learning } \\
\text { Chinese as }\end{array}$} & 2.00 & 5 & 3.1 & & Thailand & 11 & 6.8 \\
\hline & 3.00 & 118 & 73.3 & & USA & 1 & .6 \\
\hline & 4.00 & 32 & 19.9 & & Uzbekistan & 11 & 6.8 \\
\hline & 5.00 & 3 & 1.9 & & Vietnam & 2 & 1.2 \\
\hline & 6.00 & 1 & 0.6 & & Yemen & 4 & 2.5 \\
\hline & 7.00 & 2 & 1.2 & & Zambia & 7 & 4.3 \\
\hline \multirow[t]{3}{*}{ Country } & Afghanistan & 1 & .6 & & Zimbabwe & 2 & 1.2 \\
\hline & Bangladesh & 34 & 21.1 & & Others & 4 & 2.5 \\
\hline & Brazil & 3 & 1.9 & & & & \\
\hline
\end{tabular}

As far as Chinese is concerned, almost three quarters of the respondents $(74 \%)$ had learnt it as a third language as we expected, and $20 \%$ of them had learnt it as a fourth language. Authors were pleased to receive responses from students from more than 30 countries around the world, with the majority from Asia. The data from the above table proves that the respondents of the survey are international students from different regions of the globe who are learning Chinese as the third or later language during their study in China. It also signifies the relevance of the surveyed data for this research. 


\section{Data Analysis}

The collected survey data were first inserted in a spreadsheet file according to the demographic variables and construct wise questions. Then the file was fed in IBM SPSS software for arrangements and sorting. Later, common method variance, composite reliability (Anderson and Gerbing, 1988) and discriminant validity analysis were done using SmartPLS3 (Alzahrani et al., 2017; Vafaei-Zadeh et al., 2020).

After that, hypothesized relationships were tested and examined as the process is suggested and used in recent research (Alzahrani et al., 2012; Hair et al., 2014; Ramayah et al., 2011, 2013). In the process of examination, Partial Least Square (PLS) prediction algorithm was used through the use of Smart PLS 3.0 software for a full colinearity test as suggested and used by researchers recently (Shmueli et al., 2016; Ringle et al., 2015).

Path coefficient and P-Value were tested to find out if the hypothesized relationships are supported. At the end, relationship's effect size was tested with the value of f-square and finally, path coefficient and P Value have been presented alongside the hypothesized relations in a diagram.

\section{Measurement and Structural Model}

As suggested by Hair (Hair et al., 2014) at first composite reliability should be assessed along with Average Variance Extracted (AVE) to assess the reliability of the data. It is also suggested that the composite reliability should be greater than 0.7 and the Average Variance Extracted (AVE) should be greater than 0.5. Received data for all the constructs shows a value greater than 0.7 for composite reliability and also the AVE for all constructs is greater than 0.5 (Table 2).

Later Discriminant Validity for all correlations were tested as per the suggestions of Hair (Hair et al., 2020) and it was found that the diagonal values (Square root of AVE) are all greater than the other values of correlations (Table 3).

Table 2

Composite reliability and AVE

\begin{tabular}{lll}
\hline Constructs & Composite Reliability & Average Variance Extracted (AVE) \\
\hline AM & 0.875 & 0.701 \\
\hline ATL & 0.805 & 0.604 \\
\hline EM & 0.761 & 0.532 \\
\hline IM & 0.869 & 0.527 \\
\hline L2F & 0.837 & 0.563 \\
\hline PBC & 0.823 & 0.611 \\
\hline L3LIPU & 0.863 & 0.611 \\
\hline SN & 0.914 & 0.841 \\
\hline
\end{tabular}


Table 3

Discriminant validity

\begin{tabular}{lllllllll}
\hline & AM & ATL & EM & IM & L2F & PBC & L3LIPU & SN \\
\hline AM & 0.837 & & & & & & & \\
\hline ATL & -0.247 & 0.777 & & & & & & \\
\hline EM & -0.151 & 0.458 & 0.730 & & & & & \\
\hline IM & -0.297 & 0.633 & 0.556 & 0.726 & & & & \\
\hline L2F & -0.240 & 0.433 & 0.242 & 0.520 & 0.751 & & & \\
\hline PBC & -0.120 & 0.516 & 0.276 & 0.400 & 0.471 & 0.782 & & \\
\hline L3LIPU & -0.347 & 0.671 & 0.540 & 0.687 & 0.557 & 0.509 & 0.782 & \\
\hline SN & -0.033 & 0.163 & 0.187 & 0.279 & 0.073 & 0.204 & 0.216 & 0.917 \\
\hline
\end{tabular}

This meant that there is significant discriminant validity between all correlations which eventually proves that the measurement model used here is reliable and valid (Alzarani et al., 2017). The following Table 4 shows the hypothesis with their path coefficient values and P-Values to test the hypotheses whether or not they are supported. According to the cutoff values set by Hair (Hair et al., 2014) and Cohen (Cohen, 1988), it is observed that path coefficient is negative between Amotivation and L3 learning intention based on perceived usefulness which was actually assumed in the hypothesis.

The P-Values for all hypotheses are inside the cutoff range except the last hypothesis $\mathrm{H} 7$, which seems not supported by the data. For hypotheses H1-H4, H6 p-value is less than 0.01 and for $\mathrm{H} 5, \mathrm{p}$-value is less than 0.05 . It is easily concluded from the table that all hypotheses except $\mathrm{H} 7$ are supported in this research.

Table 4

Path coefficient and P-Value

\begin{tabular}{llllll}
\hline Hypothesis & Relationship & Path Coefficient & T Statistics & P Values & Remark \\
\hline H3 & AM > L3LIPU & -0.126 & 2.709 & 0.007 & Supported \\
\hline H6 & ATL > L3LIPU & 0.263 & 3.768 & 0.000 & Supported \\
\hline H2 & EM > L3LIPU & 0.193 & 3.253 & 0.001 & Supported \\
\hline H1 & IM > L3LIPU & 0.216 & 2.903 & 0.004 & Supported \\
\hline H4 & L2F > L3LIPU & 0.195 & 3.274 & 0.001 & Supported \\
\hline H5 & PBC > L3LIPU & 0.119 & 2.230 & 0.026 & Supported \\
\hline H7 & SN > L3LIPU & 0.034 & 0.607 & 0.544 & Not Supported \\
\hline
\end{tabular}

As per the suggestion of Cohen (Cohen, 1988), the f-square valuea, which represent effect size, are all at least greater than the minimum value 0.02 except the last hypothesis (H7) of which the effect is none (Table 5). 
Table 5

f-square and effect size

\begin{tabular}{lll}
\hline Relationship & f square & Effect \\
\hline AM > L3LIPU & 0.041 & Small \\
\hline ATL > L3LIPU & 0.098 & Small \\
\hline EM > L3LIPU & 0.071 & Small \\
\hline IM > L3LIPU & 0.055 & Small \\
\hline L2F > L3LIPU & 0.068 & Small \\
\hline PBC > L3LIPU & 0.026 & Small \\
\hline SN > L3LIPU & 0.003 & None \\
\hline
\end{tabular}

As for the SDT and Intention, all hypotheses $\mathrm{H} 1, \mathrm{H} 2$ and $\mathrm{H} 3$ are strongly supported. The relationship results are as follows: AM to L3LIPU (beta= $-0.126, p<0.01$ ), EM to LELIPU (beta $=0.193, p<0.01$ ), IM to L3LIPU (beta $=0.216, p<0.01$ ). For all the cases, P-Value is less than 0.01 which interprets that these hypotheses are supported.

As for the L2F and Intention, the hypothesis H4 is strongly supported as the P-Value is less than 0.01. The relationship result is as follows: L2F to L3LIPU (beta $=0.195$, $\mathrm{p}<0.01)$.

As for the TPB and Intention, the hypothesis H5 is supported and H6 is strongly supported however, H7 did not support it. The P-Value of H5 is greater than 0.01 however, less than 0.05, means supported, the P-Value of H6 is less than 0.01, which means strongly supported and the P-Value of $\mathrm{H} 7$ is greater than 0.05 , which means it is not supported by the survey data. The relationship results are as follows: PBC to L3LIPU (beta $=0.119, p>0.01$ ), ATL to L3LIPU (beta $=0.263, p<0.01$ ) and SN to L3LIPU (beta $=0.034, \mathrm{p}>0.05$ ).

The following diagram (Figure 2) shows the final result of the testing of hypotheses model with the path coefficient and p-value from the data analysis, which signifies that all the hypotheses $(\mathrm{H} 1-\mathrm{H} 6)$ are supported in this research except the last one $(\mathrm{H} 7)$. 


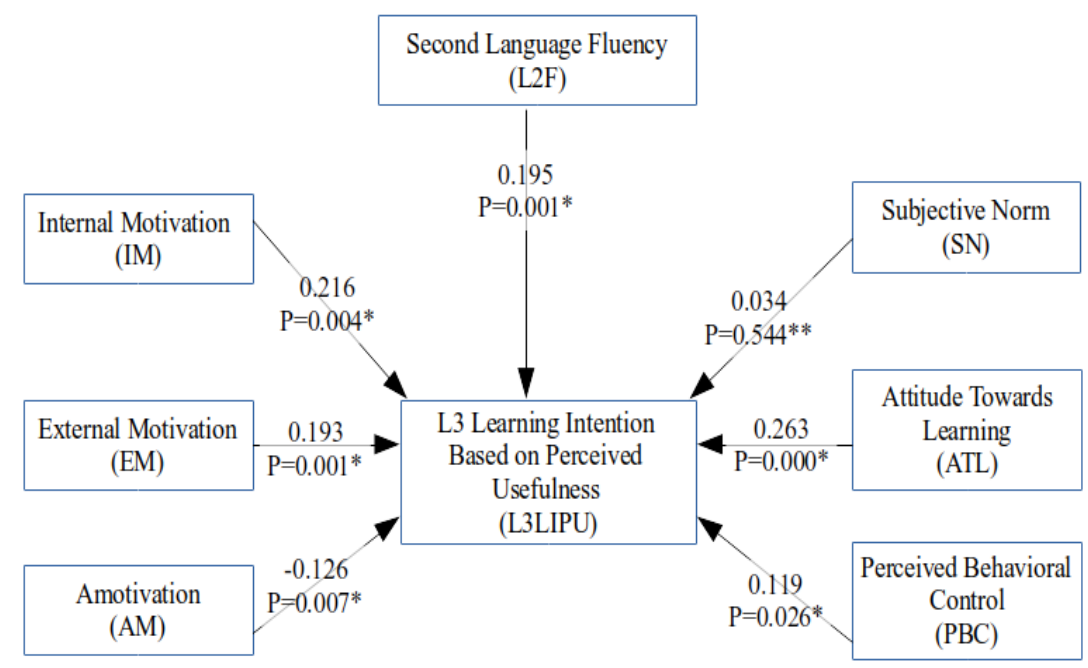

Figure 2

Testing hypothesis model

\section{DISCUSSION}

The results from the data analysis show that six of the seven hypotheses are supported and are found significant in this research. Since the factors are taken from different theorized studies, the discussion here will be under three different sections.

\section{Relationship between SDT and Learning Intention}

Three hypotheses, which were written from the constructs and drawn from the Self Determination Theory (SDT) were proved to be significant by the results of this research. According to the results, internal motivation (H1) and external motivation (H2) have a significant and positive influence on the intention of learning Chinese as a third language keeping its usefulness in mind. The path coefficients for both the relations are positive and the P-Value is less than 0.01 . The f-square value of both the relations are within the small effect size range.

Amotivation (H3) on the other hand proved to have significantly negative influence on the learning intention, as the path coefficient has a negative value. The P-Value is 0.007 which signifies that this relationship is also supported by the data as within the cutoff range.

\section{Relationship between L2S and Learning Intention}

The fluency in the second language (H4), for learning Chinese as a third language, is found to have a significant and positive influence on the learning intention. From the result it is seen that the path coefficient is positive, P-Value is 0.001 and, well within the cut off range, with f-square value at 0.068 , which signifies having a small effect. 


\section{Relationship between TPB and Learning Intention}

The last three constructs are based on the extended Theory of Planned Behavior (TPB) and it is observed that the subjective norm $(\mathrm{H} 7)$, though having a $\mathrm{P}-$ Value 0.544 is well outside the cutoff value suggested by Hair (Hair et al., 2014). Cohen (Cohen, 1988). This means that this hypothesis is not supported by the data and the f-square value, which is 0.003 for the relation, seems to have no or minimal effect. Other two constructs, attitude towards learning (H6) and perceived behavioral control (H5) have a significant and positive influence on the learning intention. The results show both the path coefficients are positive, having a P-Value 0.000 and 0.026 respectively, which are inside the cutoff range and the effect size seems to be small for both the relationships.

From the above discussion on the hypothesised relationship and its validity, it is clear that the proposed hypothesis model, based on Self Determination Theory, L2 Fluency and Theory of planned behavior to determine the learning intention for Chinese as L3, is to be accepted. As the results suggest, except the subjective norm, all the factors relating motivation, fluency in lingua franca, attitude and behavioral control have a significant influence in learning Chinese as L3 keeping the perceived usefulness of Chinese language in concern.

\section{CONCLUSION AND FUTURE RESEARCH}

This research article analyzed the Chinese language learning intention as L3 by international students studying in Chinese universities by combining the theory of planned behavior and self-determination theory as well as the fluency of L2. Authors have proved that their hypotheses, six of the seven, regarding the influencing factors for language learning intentions, keeping the perceived usefulness in mind, were supported by this research. However, this study focused on Chinese language learning intentions (as L3), was carried out on international students of four different universities in four different provinces in China and the number of respondents were limited to 161 . In this case, this number may not be enough to draw a generalized conclusion. Moreover, there could be other known and unknown factors on which further research can be carried out. Since the authors of this research focused on theory of planned behavior, selfdetermination theory and L2 fluency for this study, therefore, the results from this research can be accepted within the mentioned domain.

\section{ACKNOWLEDGEMENT}

Authors would like to express their gratitude towards the authorities of Hunan University of Humanities, Science and Technology, at Hunan in China for their permission and support to conduct this research. Authors would also like to show their gratitude to the universities, Yunnan Technology and Business University at Kunming, in Yunnan, Communication University of China in Beijing and Yangzhou University in Jiangsu, for the permission to carry out the survey for this research. The collection of survey data would have been impossible without the support of Mr. Binura Anupama and Mr. Pasindu Deepa in Hunan, Mr. Abu Saleh, in Yunnan, Mr. Obaidur Chowdhury in Beijing and Mr. Sabbir Zaman in Jiangsu province. Their continuous support and 
timely effort helped to collect data from diversified international students studying in the mentioned universities.

\section{REFERENCES}

Ajzen, I. (1985). From intention to action: A theory of planned behavior. In J. Kuhl \& J. Beckmann (Eds.), Action control: From cognition to behavior (pp. 11-40). New York: Springer.

Ajzen, I. (1991). The theory of planned behavior. Organizational Behavior and Human Decision Processes, 50, 179-211

Ajzen, I. (2002). Perceived behavioral control, self-efficacy, locus of control, and the theory of planned behavior, Journal of Applied Social Psychology, 32, 665-683.

Ajzen, I. (2005). Attitudes, personality and behaviour (2nd ed.), Maidenhead, Berkshire, England: Open University Press.

Alzahrani, A., Mahmud, I., Thurasamy, R., Alfarraj, O., \& Alwadain, A. (2021). End users' resistance behaviour paradigm in pre-deployment stage of ERP systems: evidence from Bangladeshi manufacturing industry. Business Process Management Journal. ahead-of-print No. ahead-of-print. https://doi.org/10.1108/BPMJ-08-2019-0350

Alzahrani, A. I., Mahmud, I., Ramayah, T., Alfarraj, O., \& Alalwan, N. (2017). Extending the theory of planned behavior (TPB) to explain online game playing among Malaysian undergraduate students. Telematics and Informatics, 34(4), 239-251.

Alzahrani, A., Stahl, B., Prior, M., (2012). Developing an instrument for E-Public services' acceptance using confirmatory factor analysis - Middle East Context. J. Organize. End User Comput. 24(3), 18-44.

Anderson, J.C., Gerbing, D.W., (1988). Structural equation modeling in practice: a review and recommended two-step approach. Psychol. Bull. 103(3), 411-412.

Azam, S., \& Lubna, N. (2013). Mobile phone usage in Bangladesh: The effects of attitude towards behaviour and subjective norm. Annamalai International Journal of Business Studies \& Research, 5, 25-34.

Brown, H. D. (1990). M \& Ms for language classrooms? Another look at motivation. In J. E. Alatis (Ed.), Georgetown University round table on language and linguistics (pp. 383-393). Washington, DC: Georgetown University Press.

Brown, H. D. (1994). Teaching by principles. Englewood Cliffs, NJ: Prentice Hall.

Burnkrant, R. E., \& Page, T. J. (1988). The structure and antecedents of the normative and attitudinal components of Fishbein's theory of reasoned action. Journal of Experimental Social Psychology, 24(1), 66-87. 
Cenoz, J., Hufeisen, B., Jessner, U. (2001). Cross Linguistic influence in Third Language. Bilingual Education and Bilingualism. Multilingual Matters Ltd. 31, 22-24.

Clement, R., Dornyei, Z., \& Noels, K. A. (1994). Motivation, self-confidence and group cohesion in the foreign language classroom. Language Learning, 44, 417-448.

Compeau, D. R., \& Higgins, C. A. (1995). Computer self-efficacy: Development of a measure and initial test. MIS Quarterly, 19, 189-211.

Cohen, J., (1988). Statistical Power Analysis for the Behavioral Sciences. Lawrence Erlbaum, Mahwah, NJ.

Crooks, G., \& Schmidt, R. W. (1991). Motivation: Reopening the research agenda. Language Learning, 41, 469-512.

Dangpin, W. (2010), A Study of English as a Lingua Franca in teaching Chinese to the speakers of other language. International Journal of learning, 17(6), 1-2.

Davis, F. D. (1989). Perceived usefulness, perceived ease of use, and user acceptance of information technology. MIS Quarterly, 13, 319-340.

Deci, E. L., \& Ryan, R. M. (1985). Intrinsic motivation and self-determination in human behaviour. New York: Plenum.

Dickinson, L. (1995). Autonomy and motivation: A literature review. System, 23, 165174.

Dornyei, Z. (1994). Motivation and motivating in the foreign language classroom. Modern Language Journal, 78, 273-284.

Dornyei, Z. (1990). Conceptualizing motivation in foreign-language learning. Language Learning, 40, 45-78.

Fang, F. (2017). World Englishes or English as a Lingua Franca: Where does English in China Stand? Cambridge University Press, 33(1), 19-20.

Fishbein, M., \& Ajzen, I. (1975). Belief, attitude, intention and behavior: An introduction to theory and research. Reading, Mass.: Addison Wesley.

Fornell, C., Larcker, D.F., (1981). Evaluating structural equation models with unobservable variables and measurement error. J. Mark. Res. 18(1), 39-50.

Gardner, R. C. (1985). Social psychology and second language learning. London: Arnold.

Gardner, R. C., \& MacIntyre, P. D. (1991). An instrumental motivation in language study: Who says it isn't effective? Studies in Second Language Acquisition, 13, 57-72. 
Habib, M., Siros, I. (2019). A Study of the Relationship between Iranian Learners' Sociocultural Identity and English as a Foreign Language (EFL) Learning Proficiency. International Journal of Instruction, 12(1), 53-68.

Hair, J. F., Astrachan, C. B., Moisescu, O. I., Radomir, L., Sarstedt, M., Vaithilingam, S., \& Ringle, C. M. (2020). Executing and interpreting applications of PLS-SEM: Updates for family business researchers. Journal of Family Business Strategy, 100392.

Hair, F.J., Sarstedt, M., Hopkins, L., Kuppelwieser, G. (2014). Partial least squares structural equation modeling (PLS-SEM) An emerging tool in business research. Eur. Bus. Rev. 26(2), 106-121.

Harter, S. (1982). The Perceived Competence Scale for Children. Child Development, $53,87-97$.

Hopp, T. M. (2013). Subjective norms as a driver of mass communication students: Intentions to adopt new media production technologies. Journalism and Mass Communication Educator, 68, 348-364.

House, J. (2002). Communicating English as a Lingua Franca. Eurosla yearbook 2. Hamburg University. John Benjamin Publishing Company. 243-245.

Jessner, U. (2006) Linguistics Awareness in Multilinguals: English as a Third Language. Language Arts \& Disciplines. Edinburgh University Press.

Kamada, L. D. (1986). Intrinsic and extrinsic motivational learning process: Why Japanese can't speak English. Paper presented at the Japan Association of Language Teachers' International Conference on Language Teaching and Learning, Seirei Gakuen, Hamamatsu, Japan.

Kruidenier, B., \& Clement, R. (1986). The effect of context on the composition and role of orientations in second language learning. Quebec City, Quebec: International Center for Research on Bilingualism.

Mahmud, I., Sultana, S., Rahman, A., Ramayah, T., \& Cheng Ling, T. (2020). E-waste recycling intention paradigm of small and medium electronics store managers in Bangladesh: An S-O-R perspective. Waste Management \& Research, 38(12), 14381449.

Mathieson, K. (1991). Predicting user intentions: Comparing the technology acceptance model with the theory of planned behaviour. Information Systems Research, 2, 173-191.

Noels, K. A., Pelletier, L. G., Vallerand, R. J. (2000). Why are you learning a Second language? Motivational Orientations and Self Determination Theory. Language Learning, 50(1), 55-85

Ozford, R. and Crookall, D. (1989). Research on language learning strategies: methods, findings and instructional issues. The Modern language Journal, 73(4), 404-419. 
Parvin, K., Ahmad, R. L., Reza, B. (2019). Enhancing Pilot's Aviation English Learning, Attitude and Motivation through the Application of Content and Language Integrated Learning. International Journal of Instruction, 12(1). 751-766.

Rahman, F. (2016). English language learning strategies used by Madrasa Students. Center for Pedagogy(cp). Independent University Bangladesh (IUB). 334-335.

Ramayah, T., Yeap, J.A.L., Ignatius, J., (2013). An empirical inquiry on knowledge sharing among academicians in higher learning institutions. Minerva: A Review of Science. Learning and Policy, 51(2), 131-154.

Ramayah, T., Lee, J.W.C., Boey, J.C.I. (2011). Network collaboration and performance in the tourism sector. Serv. Bus. 5(4), 411-428.

Ringle, C. M., Wende, S., Becker, J.M. (2015). Smart PLS 3. Boenningstedt: SmartPLS $\mathrm{GmbH}$.

Ryan, R. M., \& Connell, J. P. (1989). Perceived locus of causality and internalization: Examining reasons for acting in two domains. Journal of Personality and Social Psychology, 57, 450-461.

Satter, A. Z., Mahmud, A., Rahman, A., Mahmud, I., \& Akter, R. (2021). Civic engagement through restaurant review page in Facebook: a structural equation modelling approach. International Journal of Ethics and Systems, 37(2), 197-221. https://doi.org/10.1108/IJOES-06-2020-0078

Schmidt, R., Boraie, D., \& Kassabgy, 0. (1996). Foreign language motivation: Internal structure and external connections. In R. L. Oxford (Ed.), Language learning motivation: Pathways to the new century (pp. 14-87). Honolulu, HI: The University of Honolulu Press.

Shmueli, G., Ray, S., Velasquez Estrada, J.M. and Chatla, S.B. (2016). The elephant in the room: predictive performance of PLS models. Journal of Business Research,69(10), 4552-4564.

Skehan, P. (1989). Individual differences in second language learning. London: Arnold.

Taylor, S., \& Todd, P. (1995). Assessing IT usage: The role of prior experience. MIS Quarterly, 19, 561-570.

Teo, T. (2011). Factors influencing teachers' intention to use technology: Model development and test. Computers and Education, 57, 2432-2440.

Teo, T., \& Zhou, M. (2014). Explaining the intention to use technology among university students: A structural equation modeling approach. Journal of Computing in Higher Education, 26(2), 124-142. 
Teo, T., Zhou, M., Noyes, J. (2016). Teachers and Technology: development of an extended theory of planned behavior. Education Technology and research Development. Association for Educational Communications and Technology, 64(3), 1033-1052.

Thompson, R. L., Higgins, C. A., \& Howell, J. M. (1991). Personal computing: Toward a conceptual model of utilization. MIS Quarterly, 15, 124-143.

Tran, T. Q., Tran, T. N. P. (2021). Vietnamese EFL High School Students' Use of SelfRegulated Language Learning Strategies for Project-Based Learning. International Journal of Instruction, 14(1), 459-474.

Tremblay, P. F., \& Gardner, R. C. (1995). Expanding the motivation construct in language learning. The Modern Language Journal, 79, 505-518.

Ushioda, E. (1996). Learner autonomy. Dublin, Ireland: Authentik.

Vafaei-Zadeh, A., Ramayah, T., Hanifah, H., Kurnia, S., \& Mahmud, I. (2020). Supply chain information integration and its impact on the operational performance of manufacturing firms in Malaysia. Information \& Management, 57(8), 103386.

Vallerand, R. J. (1997). Toward a hierarchical model of intrinsic and extrinsic motivation. In M. P. Zanna (Ed.), Advances in experimental social psychology (Vol. 29, pp. 271-360). San Diego, CA: Academic Press.

Vallerand, R. J., Pelletier, L. G., Blais, M. R., Briere, N. M., Senecal, C., \& Vallieres, E. F. (1993). On the assessment of intrinsic, extrinsic and amotivation in education: Evidence on the concurrent and construct validity of the Academic Motivation Scale. Educational and Psychological Measurement, 53, 159-172.

Vallerand, R. J., Pelletier, L. G., Blais, M. R, Briere, N. M., Senecal, C., \& Vallieres, E. F. (1992). The Academic Motivation Scale: A measure of intrinsic, extrinsic, and amotivation in education. Educational and Psychological Measurement, 52, 1003-1017.

Vallerand, R. J., Blais, M. R., Briere, N. M., \& Pelletier, L. G. (1989). Construction et validation de l'Echelle de motivation en education (EME) [Construction and validation of the Academic Motivation Scale]. Canadian Journal of Behavioural Science, 21, 323 349 .

Venkatesh, V., Morris, M. G., Davis, G. B., \& Davis, F. D. (2003). User acceptance of information technology: Toward a unified view. MIS Quarterly, 27, 425-478. 30, 235251.

Venkatesh, V., \& Davis, F. D. (2000). A theoretical extension of the technology acceptance model: Four longitudinal field studies. Management Science, 46, 186-204.

Viorica, M., Henrike, K. B., Margarita. K. (2007). The language Experience and Proficiency Questionnaire (LEAP-Q): Assessing Language Profiles Bilinguals and 
Multilinguals. Journal of Speech, Language and Hearing Research, 50, Northwestern University. Evanston, IL. 946-948.

Wang, T. (2013), Cross linguistic Influence in Third language Acquisition: Factor influencing Inter language Transfer. Retrieved from: wwe. tc. Columbia. edu/tesolalwebjournal. 99-100

Wen, X. (1997). Motivation and language learning with students of Chinese. Foreign Language Annals,

Wong, K., Osman, R. B., Goh, P. C., \& Rahmat, M. K. (2013). Understanding student teachers' behavioural intention to use technology: Technology Acceptance Model (TAM) validation and testing. International Journal of Instruction, 6, 89-104.

Zolait, A. S. (2014). The nature and components of perceived behavioural control as an element of theory of planned behaviour. Behaviour \& Information Technology, 33, 6584. 